\title{
A SUPERVISÃO METROLÓGICA SOB A PERCEPÇÃO DO SETOR ELÉTRICO DO BRASIL: UMA PROPOSTA DE MELHORIA
}

\author{
Aline de Souza Pinto ${ }^{1}$ \\ Ruben Huamanchumo Gutierrez ${ }^{2}$
}

Resumo: O objetivo deste trabalho é avaliar e propor melhorias às atividades vinculadas à Supervisão Metrológica, aplicadas ao setor de energia elétrica. A Supervisão Metrológica é gerenciada pela Diretoria de Metrologia Legal do Inmetro e aplicada aos fabricantes de medidores de água, gás e energia elétrica, às concessionárias fornecedoras destes três serviços e recentemente aos fabricantes por todo Brasil. O estudo teve seu início a partir da identificação do problema, que trata da dificuldade de atendimento eficaz à demanda por autorizações para Autoverificação e Posto de Ensaio Autorizado para o referido setor. Para propor melhorias às atividades fez-se necessário mapear e identificar suas etapas críticas e em seguida elaborar e aplicar um questionário com um conjunto de sugestões para avaliar a percepção dos especialistas do setor elétrico e dos dirigentes da Diretoria de Metrologia Legal do Inmetro.

Propostas como a criação de documento orientativo sobre a atividade e treinamento de novas equipes de auditores surgiram a partir da convergência das questões da pesquisa entre os grupos entrevistados.

Os resultados obtidos indicam a necessidade de reestruturação no modo de resposta às solicitações das empresas autorizadas a fim de garantir a eficácia de todo o processo e consequentemente o melhor atendimento à demanda da sociedade.

Palavras-chave: Supervisão Metrológica, melhoria de processo, pesquisa de percepção.

Abstract: The aim of this work is to evaluate and propose improvements to the activities related to Metrological Supervision, applied to the electric power sector. The Metrological Supervision is managed by the Inmetro's Legal Metrology Directory, and applied to manufacturers of water, gas and electricity meters, to utilities that provide these three services and manufacturers throughout Brazil. The study started by identifying the problem, which deals with the difficulty of effective service to the demand for authorization for initial verification and Authorized Testing Station for that sector. To propose improvements to the activities it was necessary to map and identify its critical steps, and then develop and implement a questionnaire with a set of tips for evaluating the perception of power sector experts and officials of Inmetro's Legal Metrology Directory.

Proposals such as the creation of a guidance document about the activity and training new teams of auditors to perform an activity under supervision of Legal Metrology Directory emerged from the convergence of research questions among the groups surveyed.

The results indicate the need to restructure in order to respond to requests from authorized companies to ensure the effectiveness of the whole process and therefore better serve the needs of society.

Keywords: Metrological Supervision, process improvement, perception research.

\footnotetext{
${ }^{1}$ Instituto Nacional de Metrologia, Qualidade e Tecnologia - Dir. de Metrologia Legal. Duque de Caxias, RJ. aspinto@inmetro.gov.br

22Universidade Federal Fluminense - Eng. de Produção. Niterói, RJ. rubenhg@ uol.com.br
}

ENGEVISTA, V. 16, n. 3, p.292-313, Setembro 2014 


\section{INTRODUÇÃO}

O Instituto Nacional de Metrologia, Normalização e Qualidade Industrial (Inmetro) é uma Autarquia Federal que tem por objetivo maior garantir o bem estar da sociedade e a competitividade da economia por meio da metrologia e da qualidade. Dentre suas competências e atribuições destaca-se a de verificar a observância das normas técnicas e legais, no que se refere às unidades de medida, métodos de medição, medidas materializadas, instrumentos de medição e produtos pré-medidos.

O Inmetro é responsável por organizar e executar as atividades de metrologia legal no Brasil, por meio da sua Diretoria de Metrologia Legal (Dimel), cujas atribuições englobam o controle metrológico de instrumentos de medição. Novos instrumentos de medição devem ter seu modelo aprovado pelo Inmetro, que examina, ensaia e verifica se o mesmo está adequado para a sua finalidade. Após a fabricação, cada instrumento deve ser submetido à verificação inicial para assegurar sua exatidão antes do uso e, quando está em utilização, o seu detentor é o responsável pela manutenção dessa exatidão e uso correto, sendo o mesmo controlado por verificações periódicas e inspeções. Para o efetivo cumprimento de tal controle, chamado controle metrológico, por todo o país, o Inmetro optou por uma estrutura descentralizada, contando com o apoio da Rede Brasileira de Metrologia Legal e Qualidade (RBMLQ) que é formada por órgãos metrológicos regionais, os Institutos de Pesos e Medidas (IPEM), distribuídos por todos os Estados e responsáveis pela execução das verificações e inspeções relativas aos instrumentos de medição, dentre outras atividades. Porém, a Organização Internacional de Metrologia Legal (OIML), vem ao longo da última década dando ênfase à necessidade de uma mudança no contexto da execução da metrologia legal, introduzindo práticas de avaliação da conformidade. Esta mudança está refletida na supervisão metrológica, modalidade de controle metrológico aplicada às concessionárias de energia elétrica, gás e água e aos fabricantes de instrumentos de medição nos respectivos campos, além de fabricantes de medidores de pressão sanguínea arterial (esfigmomanômetros) e de medidores / registradores de velocidade e distância percorrida por veículos (cronotacógrafos), focada numa atuação voltada para ação preventiva, supervisão e auditoria na execução destas atividades.

As atividades de supervisão metrológica impactam diretamente as concessionárias e fabricantes, fazendo-se necessário avaliar a eficácia do seu processo operacional com o objetivo de se instituir uma sistemática de melhoria contínua ao atendimento à demanda proveniente do setor produtivo. A elaboração desta proposta de melhoria baseada na percepção do setor elétrico do Brasil representa o desafio do presente trabalho.

\section{REVISÃO BIBLIOGRÁFICA}

\subsection{METROLOGIA LEGAL}

Parte da metrologia relacionada às atividades resultantes de exigências obrigatórias, referentes às medições, unidades de medida, instrumentos de medição e métodos de medição, e que são desenvolvidas por organismos competentes (Portaria Inmetro $\mathrm{n}^{\circ} 163$, 2005, p.10).

Segundo Réche (2004), quando a metrologia aplicada é praticada conforme a lei, pode ser chamada de metrologia legal.

A Metrologia Legal teve sua origem na necessidade de assegurar um comércio justo e uma de suas mais importantes contribuições para a sociedade é o seu papel de aumentar a eficiência no comércio mantendo a confiança nas medições e reduzindo os custos das transações. Seu objetivo maior no aspecto econômico é proteger as relações de consumo, ou seja, estabelecer transparência e confiança entre vendedor e comprador no que diz respeito ao produto que está sendo comercializado, sem gerar benefício para quaisquer das partes, ou melhor, com imparcialidade. 
A Metrologia Legal atende tais necessidades principalmente através de regulamentos, os quais são implementados para assegurar um nível adequado de credibilidade nos resultados de medição. Em todas as suas aplicações, a Metrologia Legal cobre unidades de medida, instrumentos de medição e outras áreas tais como a dos os produtos prémedidos.

Também são submetidos à supervisão governamental em países desenvolvidos, instrumentos de medição usados em atividades oficiais, no campo médico, na fabricação de medicamentos, bem como nos campos de proteção ocupacional, ambiental e da radiação. A Metrologia Legal também apresenta influência direta na qualidade de vida da sociedade, quando cuida de aspectos relacionados à saúde e segurança do cidadão.

\subsection{O CONTROLE METROLÓGICO}

Controle Metrológico é uma expressão que designa hoje o controle efetuado pelo Estado dos instrumentos de medição, nomeadamente os utilizados nas transações comerciais, na saúde, na segurança, na proteção do consumidor e do meio ambiente, e que, por lei, estão submetidos a esse controle.

A Metrologia Legal permeia todos os níveis e setores de uma nação desenvolvida. Grande número de instrumentos de medição que está em contato constante com a vida do cidadão está sujeito à regulamentação metrológica. As ações governamentais no campo da metrologia legal objetivam, por um lado, a disseminação e manutenção de medidas e unidades harmonizadas, e de outro, a supervisão e exame de instrumentos e métodos de medição. Sendo assim, no que diz respeito à exatidão e às medidas fornecidas por estes instrumentos, é tarefa do controle metrológico estabelecer adequada transparência e confiança entre as partes usuárias, com base em ensaios imparciais.

O Controle Metrológico compreende: a Perícia Metrológica, O Controle legal dos Instrumentos de Medição ou Medidas
Materializadas e a Supervisão Metrológica, tema do presente estudo.

\subsection{VERIFICACÕES INICIAIS E SUBSEQÜENTES}

A verificação é um procedimento que compreende o exame, a marcação e (ou) emissão de um certificado que constata e confirma que o instrumento satisfaz às exigências regulamentares(3.12, VIML, 2005).

- A verificação inicial de um instrumento de medição é aquela realizada no instrumento pela primeira vez antes de sua colocação em uso.

- A verificação subsequente é aquela realizada após a verificação inicial, incluindo a verificação após reparos, manutenção e calibração e, após reprovação ou a pedido do usuário, e a verificação periódica obrigatória, efetuada em intervalos de tempo especificados, geralmente de um ano, e segundo procedimento fixado em regulamento.

\subsection{A REDE BRASILEIRA DE} METROLOGIA LEGAL -QUALIDADE $O$ Instituto Nacional de Metrologia, Normalização e Qualidade Industrial, na figura da Diretoria de Metrologia Legal, é o representante do Estado responsável por gerir o controle metrológico legal em território nacional, além de trabalhar para assegurar que a metrologia legal seja uniformemente aplicada no mundo inteiro, realizando um papel ativo em cooperação com o MERCOSUL e a Organização Internacional de Metrologia Legal (OIML).

Motivado pela grande extensão territorial, o Inmetro optou por um modelo descentralizado, delegando a execução do controle metrológico aos Órgãos Metrológicos Estaduais - conhecidos por Ipem, Instituto de Pesos e Medidas, que fazem parte da Rede Brasileira de Metrologia Legal e Qualidade - Inmetro (RBMLQ-I).

A Rede é composta por 26 órgãos metrológicos regionais, dos quais 23 fazem parte da estrutura dos governos estaduais, um órgão é municipal e outros dois restantes são administrados pelo 
próprio Inmetro. Esta estrutura vem garantindo a execução das atividades em todos os pontos do território nacional, com sedes nos 26estados da federação, agências em 65 cidades do interior e 23 postos de verificação de veículos-tanque localizados em polos de distribuição de combustíveis automotivos.

A RBMLQ-I é o braço executivo do Inmetro em todo o território brasileiro, executando as verificações e inspeções relativas aos instrumentos de medição e às medidas materializadas regulamentadas e o controle da exatidão das indicações quantitativas dos produtos pré-medidos, de acordo com a legislação em vigor. Efetua o controle de equipamentos e instrumentos para assegurar que os consumidores estão recebendo medidas corretas.

\subsection{A SUPERVISÃO METROLÓGICA}

A supervisão metrológica é o controle exercido na produção, importação, instalação, uso, manutenção e reparo de instrumentos de medição, com $o$ propósito de verificar se tais instrumentos estão sendo usados corretamente, garantindo a observância das leis e regulamentos metrológicos (3.3, VIML, 2005).É uma modalidade de atuação da Metrologia Legal na qual as empresas que fabricam, importam ou recondicionam instrumentos de medição sujeitos ao controle metrológico são submetidas, de forma voluntária, com o propósito de manter a autorização para realizar os ensaios de verificação em seus próprios instrumentos.

\section{HISTÓRICO DA SUPERVISÃO METROLÓGICA}

Até o ano de 2005, todo instrumento de medição sujeito ao controle metrológico no Brasil - com exceção dos medidores de energia elétrica e de gás, cujos controles se limitavam à apreciação técnica de modelo - tinha seu controle realizado pelos Ipem, que dispunham de equipes de metrologistas destinados a realizar as verificações iniciais nos instrumentos antes de sua comercialização em seu local de fabricação e as verificações subsequentes, tanto após o reparo quanto as periódicas, no local de utilização dos mesmos. Tal controle era realizado na totalidade de instrumentos, sem levar em consideração as práticas de avaliação da conformidade, como por exemplo, sistemas de gestão, infraestrutura laboratorial e capacitação de recursos humanos. Porém, com o crescimento da demanda da indústria e da sociedade, mudanças no cenário econômico em função da globalização, modernização da tecnologia e necessidade de entrada de novos produtos sob regulamentação, o modelo de controle metrológico vigente até aquele momento, cuja operacionalização encontrava-se sob responsabilidade dos Estados, tornou-se ineficiente e posteriormente inviável.

Sendo assim, Réche (2004) fez o levantamento do estado da arte em Metrologia Legal, mostrando em seu trabalho de pesquisa: "Novas Formas de Atuação para a Metrologia Legal no Brasil", o contexto internacional, as formas de atuação da metrologia legal na Comunidade Europeia (mais especificamente Portugal, Espanha e Alemanha), o panorama da Metrologia Legal no Brasil, as perspectivas futuras para as próximas décadas e assim propõe um modelo de atuação compatível com a realidade brasileira.

Naquele momento, o modelo de atuação na área de serviços públicos tinha o seguinte perfil:

$\checkmark$ Para medidores de energia elétrica e medidores de gás domiciliares só se realizava apreciação técnica de modelo, pelo Inmetro.

$\checkmark$ Para hidrômetros, além da apreciação técnica feita pelo Inmetro, os Ipem já realizavam verificação inicial, porém somente em alguns estados.

O início da discussão sobre as melhores formas de implantação do controle metrológico via Supervisão Metrológica surgiu a partir do segmento de energia elétrica, por ser o setor que apresenta a maior demanda por instrumento em nível nacional, porém, semelhanças estruturais nos segmentos de água e gás levaram a 
expansão do modelo para a área de serviços de utilidade pública, englobando estas três modalidades. Então, com a criação da Portaria Inmetro no 066 em 13 de Abril de 2005, surge a Supervisão Metrológica no Brasil, como uma alternativa ao controle metrológico tradicional, com o objetivo de autorizar fabricantes de medidores de energia elétrica eletromecânicos, hidrômetros e medidores de gás domiciliares a realizar autoverificação, e prestadoras de serviços públicos no âmbito da energia elétrica, água e gás, que dispõem de laboratórios próprios ou contratados para realizar o reparo de seus instrumentos, a atuar como Postos de Ensaio Autorizados, ou seja, a realizar a verificação após o reparo destes instrumentos em suas instalações próprias ou contratadas. A proposta de atuação é pautada não somente na avaliação física de cada instrumento em questão como também na avaliação sistêmica, ou seja, da infraestrutura, da observância de boas práticas de laboratório, do treinamento de pessoal, da rastreabilidade da medição, seguindo requisitos de Sistemas de Gestão, tanto na qualidade de serviços (normas ISO série 9000) quanto para laboratórios de ensaio e calibração (norma ISO/IEC 17025).

Esta modalidade do controle metrológico foi idealizada para atender ao segmento de medição de energia elétrica, gás e água (serviços de utilidade pública), porém, a Portaria Inmetro $\mathrm{n}^{\mathrm{o}}$ 066/05 não apresentava um item claro que restringisse a utilização do modelo a estes três tipos de instrumentos. Sendo assim, ocasionou o surgimento de demandas para outros tipos de instrumentos, como por exemplo, para o setor de balanças comerciais. Porém, foi feito um levantamento - tomando-se por base a Lei $\mathrm{n}^{\mathrm{o}} 10.829$ de 23 de dezembro de 2003, que trata das Taxas de Serviços Metrológicos - evidenciando-se que a adesão à Supervisão Metrológica de algumas empresas deste setor poderia levar a um desequilíbrio de mercado, visto que os valores praticados na modalidade de autoverificação para cada unidade de instrumento são consideravelmente inferiores aos valores praticados para verificação inicial, ou seja, esta medida poderia causar sérios impactos às empresas que não possuíssem recursos para realizar investimentos a fim de aderir à autoverificação. Logo, não cabendo à política do Inmetro interferir nas relações de mercado e de concorrência justa, fezse necessário o exame quanto ao impacto no setor de cada instrumento sujeito ao controle metrológico legal cujas empresas se candidatavam à adesão ao modelo em discussão. Assim, estes estudos ocasionaram a publicação da Resolução Conmetro $\mathrm{n}^{\circ}$ 013, de 20 de dezembro de 2006, que define que as atividades de verificação inicial e verificação após reparos poderiam ser substituídas pela supervisão metrológica somente para estes três tipos de instrumentos.

Antes da publicação da referida resolução surgiu uma demanda para autorização para autoverificação de empresa importadora de esfigmomanômetros (medidores de pressão arterial). A análise realizada para este mercado detectou que a abertura do modelo para tal instrumento não causaria impactos relevantes nas relações mercadológicas entre os atores deste cenário. No caso dos cronotacógrafos, o fator crítico que levou à análise da possibilidade de abertura do modelo para este mercado foi a enorme demanda pelo instrumento em território nacional. Sendo assim, foi publicada a Resolução Conmetro $n^{\circ}$ 04, de 6 de setembro de 2007, permitindo a substituição do controle metrológico tradicional pelas atividades de autoverificação também para cronotacógrafos e esfigmomanômetros.

\section{METODOLOGIA}

Considerando-se a especificidade do tema, utilizou-se o procedimento metodológico detalhado a seguir:

Foi feita uma revisão bibliográfica sobre o assunto utilizando-se de documentos da Organização Internacional de Metrologia Legal, artigos publicados sobre o tema e documentos emitidos pelo Inmetro, entre os quais da Diretoria de Metrologia Legal. 
Após a revisão bibliográfica, funcionários do Inmetro envolvidos na atividade foram consultados tendo como resultado $\mathrm{o}$ mapeamento do processo operacional de Supervisão Metrológica, tanto para Postos de Ensaio Autorizados como para Autoverificação, da solicitação do cliente até sua conclusão.

Em seguida, com base nas solicitações de autorização registradas no Inmetro, foi feito um levantamento quantitativo do panorama da atividade no Brasil, mostrando as fases em que cada processo se encontra; a quantidade de autorizações e de processos cancelados; a distribuição por estados por tipo de autorização; as auditorias periódicas geradas; a situação do setor elétrico no Brasil em termos de empresas autorizadas; dentre outros indicadores. A análise foi realizada nos processos abertos a partir do mês abril de 2005, ano em que a atividade teve seu início, até o mês de junho do ano de 2009. O planejamento das auditorias periódicas foi feito até janeiro de 2010.

Após o levantamento dos indicadores, foi realizada uma entrevista com um especialista em Metrologia Legal, a fim de se enumerar os problemas da atividade.

Baseado nas respostas encontradas na fase anterior foi elaborado um questionário com o objetivo de se perceber a visão dos gestores da Diretoria de Metrologia Legal e das empresas do setor elétrico autorizadas quanto aos apontamentos do especialista em Metrologia Legal entrevistado, a fim de se encontrar pontos convergentes que serão alvo de ações de melhoria da atividade. A pesquisa foi feita utilizandose a escala de medida de Likert, que é uma escala somatória e direta. Os respondentes são solicitados a concordar ou discordar das afirmações, informando qual seu grau de concordância/discordância. A cada resposta é atribuído um número que reflete a direção da atitude do respondente em relação à afirmação. A pontuação total de uma dada opção é obtida pelo somatório das pontuações de cada respondente. Comparando-se esta pontuação com a máxima possível, ou seja, a pontuação caso todos os respondentes elegessem o maior grau de concordância, fornece-se um percentual importante para análise da veracidade do item (Rodrigues, 2005).

Em todos os casos, os respondentes deveriam marcar sua opinião sobre a afirmação feita, variando de um mínimo de 1 (discordo totalmente) até um máximo de 5 (concordo totalmente). Para cada item foi deixada a opção "Não sei opinar” $(\mathrm{N})$, para evitar possíveis ambiguidades que as pontuações que ocupam as posições centrais da escala pudessem causar, além de um espaço para considerações adicionais, consideradas relevantes para a pesquisa. Em seguida houve o tratamento e análise dos dados obtidos do referido questionário.

A etapa seguinte trata da estruturação da proposta de melhoria

como solução para o problema definido no início do trabalho.

A última etapa contempla as conclusões e pesquisas futuras sobre o assunto.

\section{O ESTUDO DE CASO}

A atividade de Supervisão Metrológica (SM) teve seu início na Diretoria de Metrologia Legal do Inmetro em 2005, com a publicação da Portaria $\mathrm{n}^{\circ} 066$ de 13 de abril de 2005. A Divisão de Serviços Metrológicos (Disem), responsável pela gestão da atividade, definiu suas etapas e elaborou modelos de documentos em adequação aos demais processos gerenciados pela Diretoria de Metrologia Legal (Dimel).

\subsection{O PROCESSO OPERACIONAL DA SUPERVISÃO METROLÓGICA}

Para melhor visualização das etapas principais, o macroprocesso operacional da atividade de SM pode ser descrito conforme esquema da figura1. 


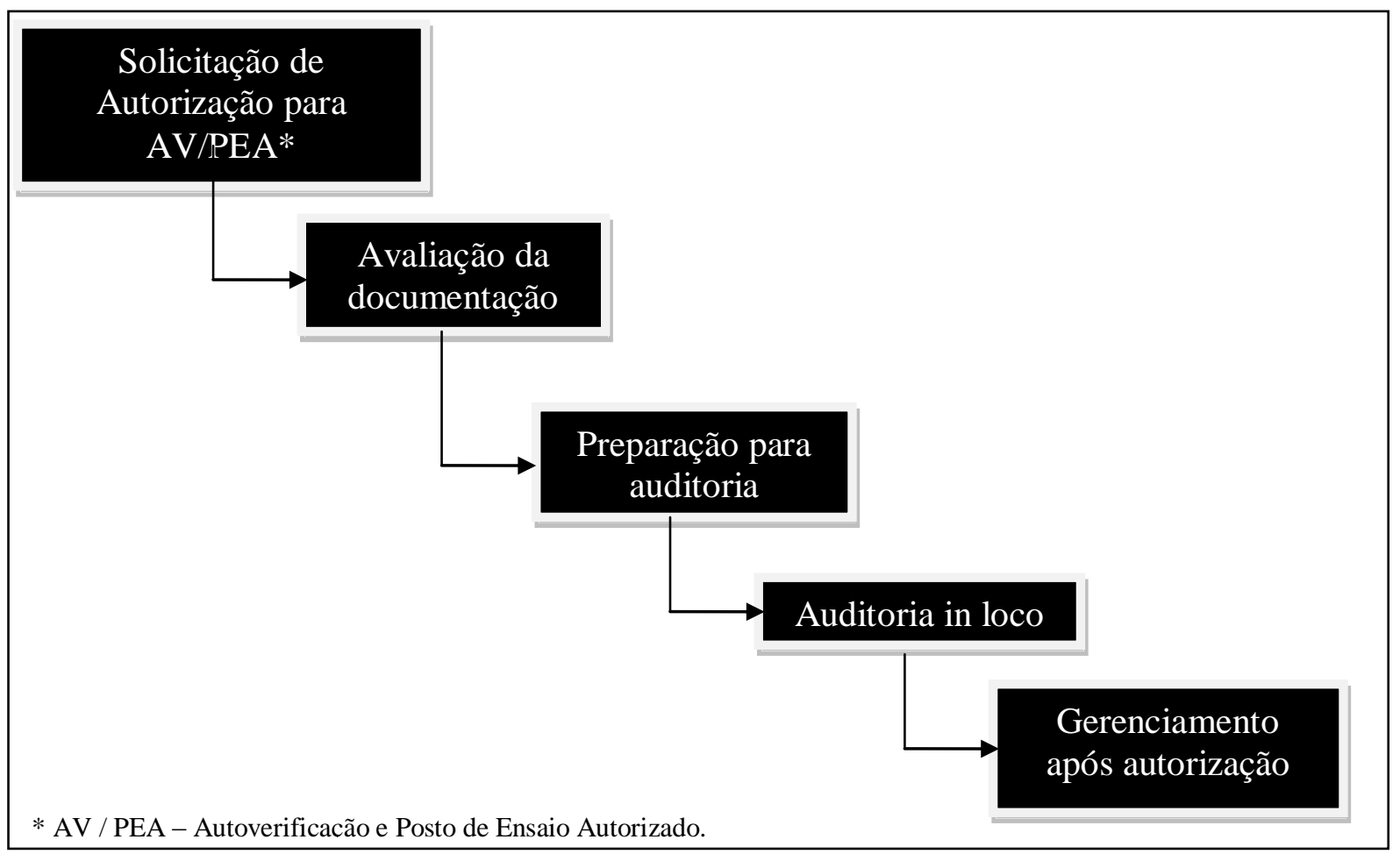

Figura 1: Macroprocesso de SM.

Fonte: Próprio Autor

4.1.1 - Solicitação de Autorização para AV/PEA: consiste no envio para o Inmetro da documentação necessária à autorização da empresa interessada. Nesta etapa será realizada a abertura física do processo e estimada a quantidade de homem-hora a ser utilizada na realização do serviço. A análise que é feita nesta fase trata da exequibilidade do serviço e da completeza dos documentos. 4.1.2 - Avaliação da documentação: Nesta etapa é verificado se a empresa interessada possui infraestrutura adequada, número mínimo de pessoal treinado, padrões, bancadas e equipamentos necessários à realização dos ensaios na quantidade de instrumentos proposta, além de procedimentos para realização destes ensaios, e um sistema da qualidade implementado por meio do seu manual da qualidade. Caso estas exigências sejam atendidas o auditor líder procede com o agendamento da auditoria inicial e preparação da auditoria.

4.1.3 -Preparação da auditoria: Consiste na seleção dos equipamentos a serem utilizados na auditoria, preparação da lista de verificação e elaboração do plano de auditoria. Este plano é enviado à empresa interessada contendo todas as informações necessárias à realização da auditoria in loco, desde a legislação na qual a auditoria será baseada até os dias e horários dos voos dos auditores.

4.1.4 - Auditoria in loco: Esta fase do processo começa com uma reunião inicial entre auditores e auditados e é seguida pela coleta das amostras que serão ensaiadas, análise documental, entrevistas com as pessoas chave da organização e verificação da conformidade ao modelo aprovado. Posteriormente são verificadas as condições ambientais do local e realizado o acompanhamento dos ensaios. Caso haja não conformidades, estas devem ser registradas no relatório parcial de auditoria. Ao fim dos trabalhos, o auditor líder apresenta o relatório parcial de auditoria à empresa auditada, dando um prazo para a correção das não conformidades (NC). Solucionadas as $\mathrm{NC}$, o relatório final é encaminhado à comissão da Diretoria de Metrologia Legal para sua análise, e caso seja aprovado é elaborada a portaria de autorização, que é liberada à empresa após o pagamento das despesas do processo. 
4.1.5 - Gerenciamento após a autorização: Esta etapa trata do controle dos lacres e marcas de verificação / numeração identificadora, auditorias periódicas, ampliações de escopo, auditorias extraordinárias e atendimento à empresa autorizada.
4.2 O PANORAMA DA ATIVIDADE

A atividade de Supervisão Metrológica é realizada por cinco auditores da Disem. Á época do estudo a Disem possuía 154 processos cadastrados em seu sistema de informação, dos quais 95 já haviam sido autorizados. O referido quantitativo se divide conforme Figura 2:

\section{Dis tribuição dos Processos de SM Autorizados}

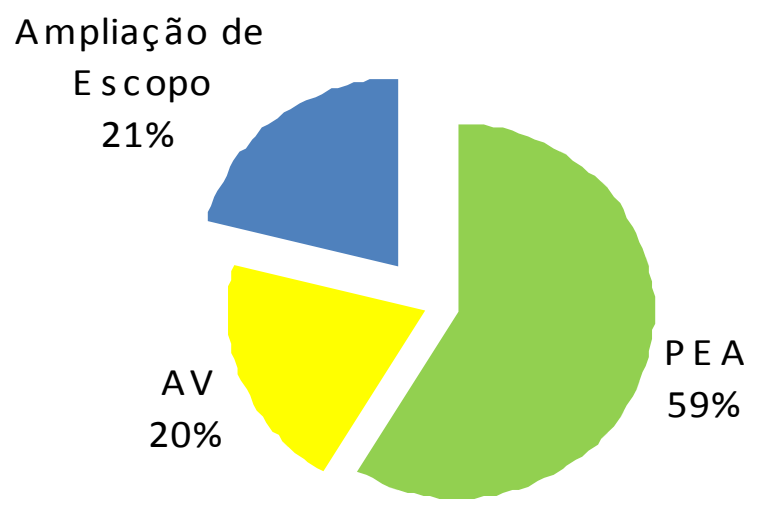

Processos Autorizados: 95

Figura 2: Distribuição dos processos de SM autorizados (2005 - 2009)

Fonte: Próprio Autor (2009)

Cada processo referente à autorização para Autoverificação (AV) ou Posto de Ensaio Autorizado (PEA), seis meses após a concessão da autorização, deve gerar um novo processo, relacionado ao primeiro, para a realização da chamada Supervisão Metrológica Periódica. O item 3.4.2 da Portaria $n^{\circ} 066$ de 13 de abril de 2005 prevê estas auditorias e também define a periodicidade das demais auditorias subsequentes à autorização, pois após a publicação da portaria de autorização, este processo torna-se contínuo e infindável. Destes 95 processos autorizados somente 73 geram processos de SM periódica, pois os outros 22 referem-se à ampliação de escopo, etapa da atividade que não requer avaliação periódica específica, pois 0 escopo completo da autorização deve ser verificado na auditoria periódica seguinte à sua ampliação.
Dos 73 processos de SM Periódicas a serem abertos seis meses após a autorização, apenas $43 \%$ foram realizados, porém com um significativo atraso. A fim de explicitar este atraso, a Figura 3 mostra 16 empresas que foram autorizadas durante o ano de 2006 e que tiveram sua primeira auditoria periódica realizada muito após os seis meses seguidos de sua autorização conforme a legislação.

Com o objetivo de perceber a real demanda pela atividade de manutenção da autorização foi feito o planejamento de todas as auditorias a ser realizadas nas empresas autorizadas até janeiro de 2010 , tomando-se por marco o mês de julho de 2006, no qual a primeira auditoria periódica da primeira empresa autorizada deveria ter ocorrido. 
Processos Autorizados em 2006:

Previsão x Realização das Periódicas
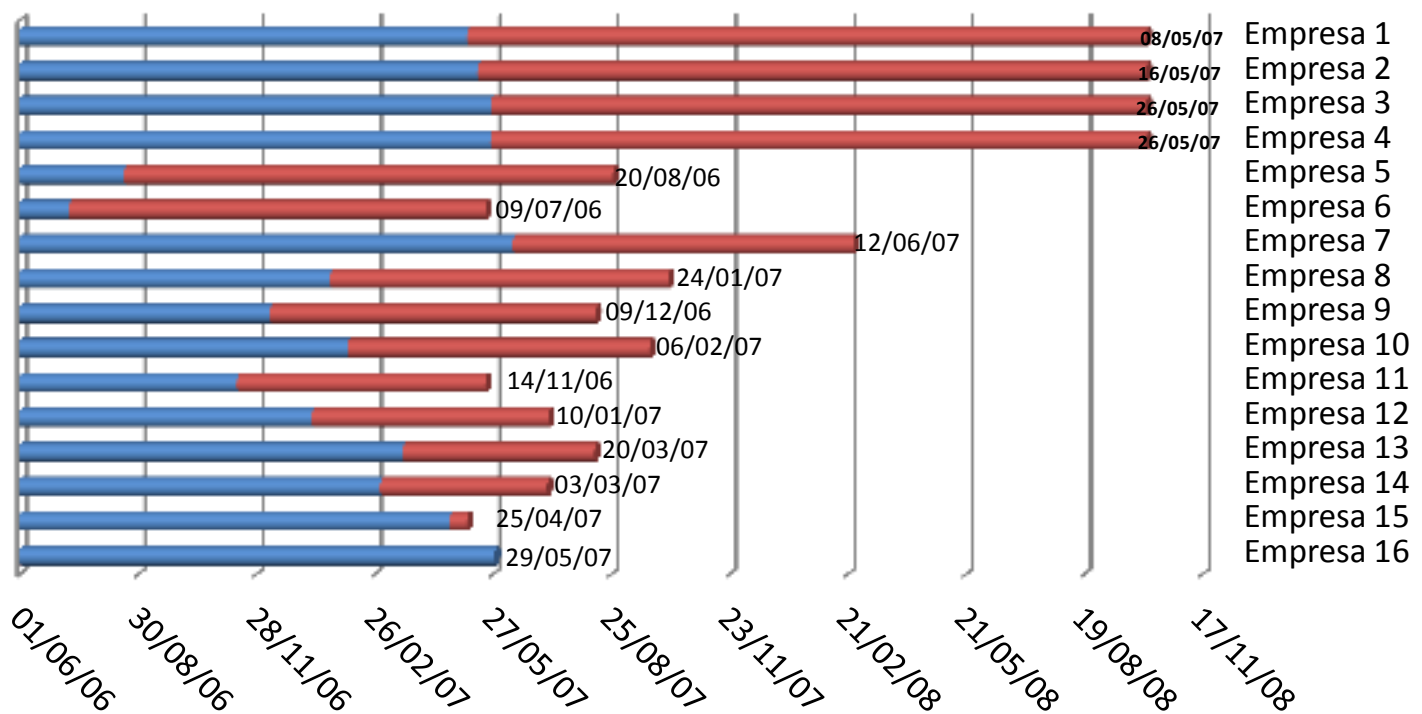

- Previsão nealização

Figura 3: processos autorizados em 2006: Previsão x Realização de Periódicas Fonte: Próprio Autor

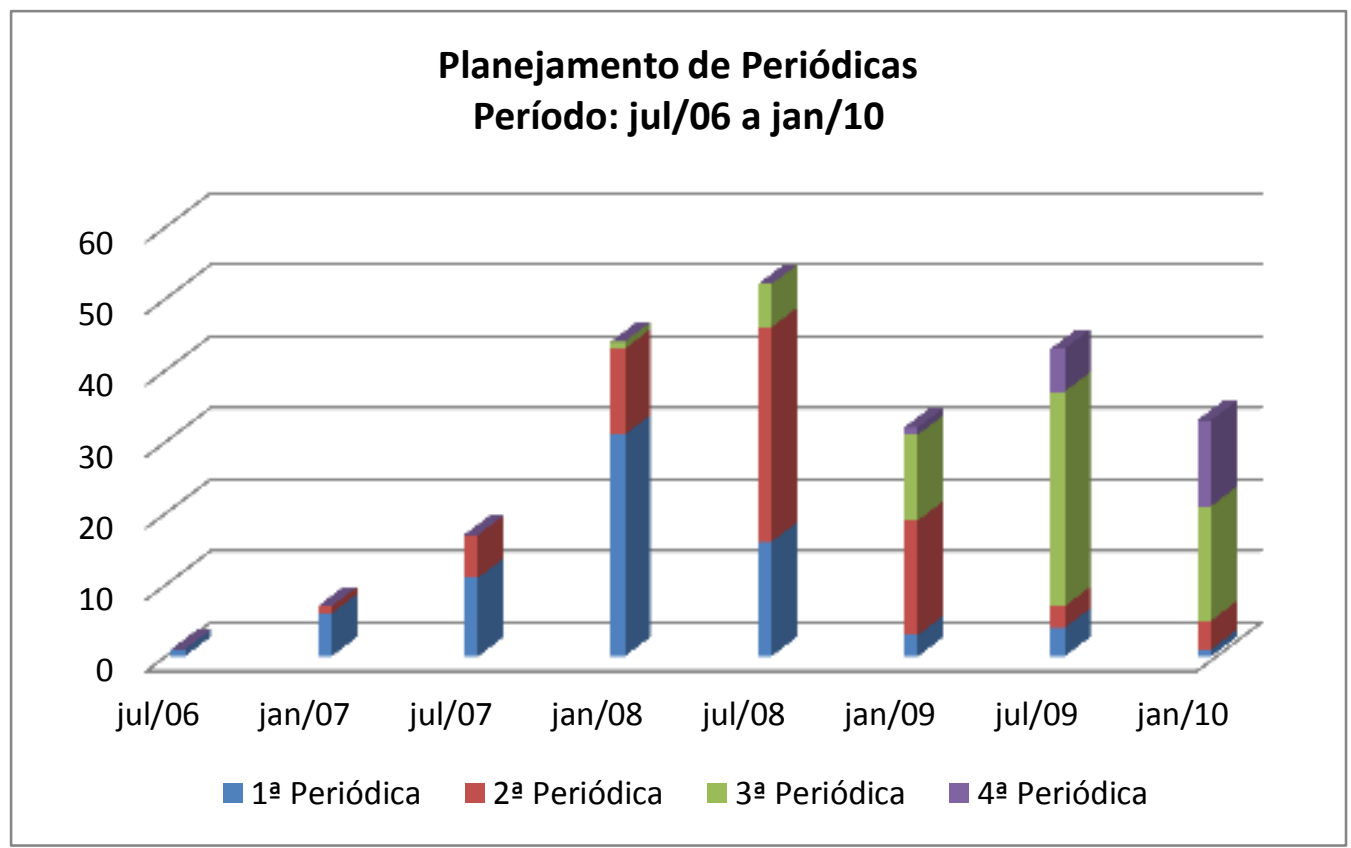

Figura 4: Planejamento das periódicas de jul/06 a jan/10

Fonte: Próprio autor

A figura 5 a seguir mostra a comparação entre o total de auditorias planejadas, conforme figura 4 acima e o total realizado até Julho de 2009. 


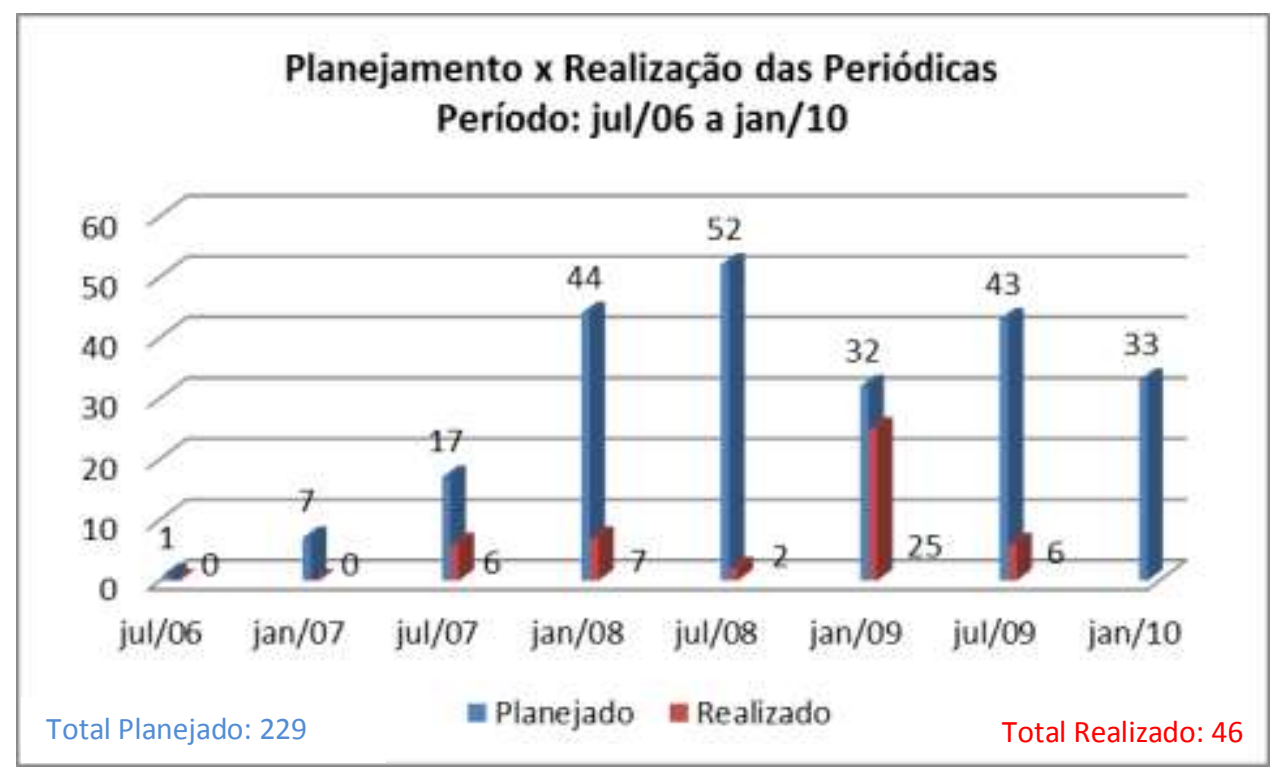

Figura 5: Planejamento x Realização das SM Periódicas de jul/06 a jan/10 Fonte: Próprio autor

Vale ressaltar que o panorama exposto trata somente dos processos finalizados até julho de 2009 e que geraram auditorias periódicas, não se levando em conta o aumento da demanda posterior devido ao surgimento de novos solicitantes por autorizações.

\subsection{PANORAMADA SUPERVISÃO} Metrológica para o setor elétrico no Brasil
Como forma de visualizar a distribuição da demanda por autorizações de AV e PEA pelos setores da indústria nacional foi feito o levantamento por tipo de instrumento. $\mathrm{O}$ atendimento efetivo desta demanda, ou seja, os processos autorizados, também foram distribuídos por tipo de instrumento. Estas distribuições ocorrem conforme a Figura 6 ilustrada abaixo:

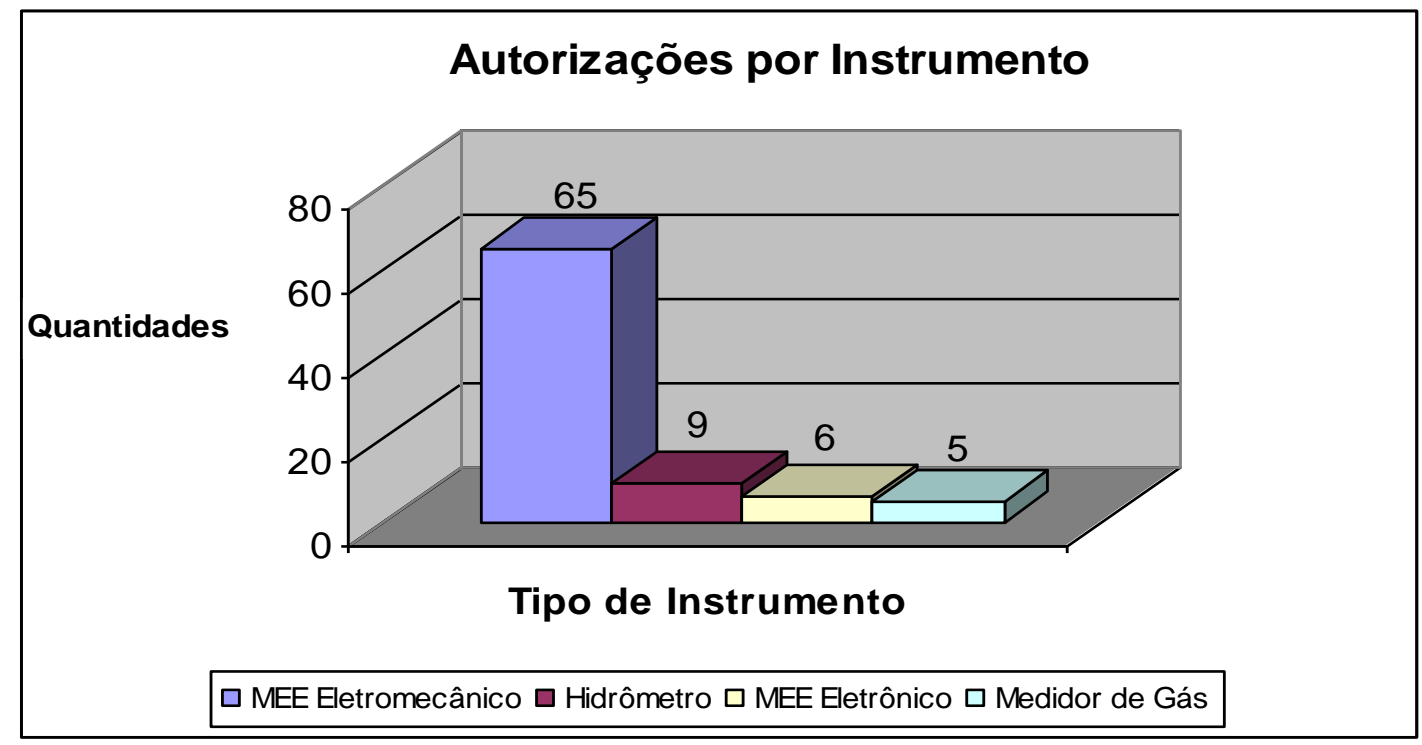

*MEE = Medidor de Energia Elétrica

Figura 6: Autorizações por Instrumentos

Fonte: Próprio autor (junho de 2009)

É visto que o maior demandante pela atividade junto ao Inmetro é o setor de energia elétrica, pois 71 autorizações para
AV e PEA são para empresas fabricantes de medidores de energia elétrica e concessionárias do referido setor. 
O mercado brasileiro absorve cerca de 3 a 4 milhões de medidores de energia elétrica por ano, sendo que no ano de 2008, 60\% dos medidores comercializados para a indústria nacional foram de tecnologia eletrônica. Cerca de 2,5 a 3 milhões de novos consumidores, dentre residenciais e industriais, surgem anualmente, e o mercado de substituição é constituído por 700 mil a 1 milhão de instrumentos/ano. A capacidade produtiva do setor é de 10.000.000 de instrumentos por ano (www.abinee.org.br, acesso em 17 de julho de 2009). De acordo com o Plano Decenal de Expansão de Energia 2019 elaborado pela Empresa de Pesquisa Energética, as projeções do número total de domicílios particulares permanentes do Brasil e das regiões para o período de 2010 a 2019 são apresentadas conforme a tabela 1 a seguir:

Tabela 1: Brasil e Regiões, 2010-2019: Projeção do Número de Domicílios (mil) Fonte: Elaboração EPE.

\begin{tabular}{ccccccc}
\hline Ano & Norte & Nordeste & Sudeste & Sul & Centro-Oeste & Brasil \\
\hline $\mathbf{2 0 1 0}$ & 4.259 & 15.295 & 27.152 & 9.591 & 4.547 & 60.844 \\
$\mathbf{2 0 1 4}$ & 4.725 & 16.660 & 29.692 & 10.533 & 5.051 & 66.662 \\
$\mathbf{2 0 1 9}$ & 5.305 & 18.384 & 32.917 & 11.723 & 5.663 & 73.992 \\
\hline \multicolumn{7}{c}{ Variação (\% ao ano)* } \\
\hline $\mathbf{2 0 1 0 - 2 0 1 4}$ & 2,6 & 2,2 & 2,3 & 2,4 & 2,7 & 2,3 \\
$\mathbf{2 0 1 5 - 2 0 1 9}$ & 2,3 & 2,0 & 2,1 & 2,2 & 2,3 & 2,1 \\
$\mathbf{2 0 1 0 - 2 0 1 9}$ & 2,5 & 2,1 & 2,2 & 2,3 & 2,5 & 2,2 \\
\hline \multicolumn{7}{c}{ Estrutura de Participação (\%) } \\
\hline $\mathbf{2 0 1 0 - 2 0 1 4}$ & 2,6 & 2,2 & 2,3 & 2,4 & 2,7 & 2,3 \\
$\mathbf{2 0 1 5 - 2 0 1 9}$ & 2,3 & 2,0 & 2,1 & 2,2 & 2,3 & 2,1 \\
$\mathbf{2 0 1 0 - 2 0 1 9}$ & 2,5 & 2,1 & 2,2 & 2,3 & 2,5 & 2,2 \\
\hline
\end{tabular}

Notas: Domicílios em 31 de dezembro.

(*) Variações médias anuais nos períodos indicados, a partir de 2009 e 2014

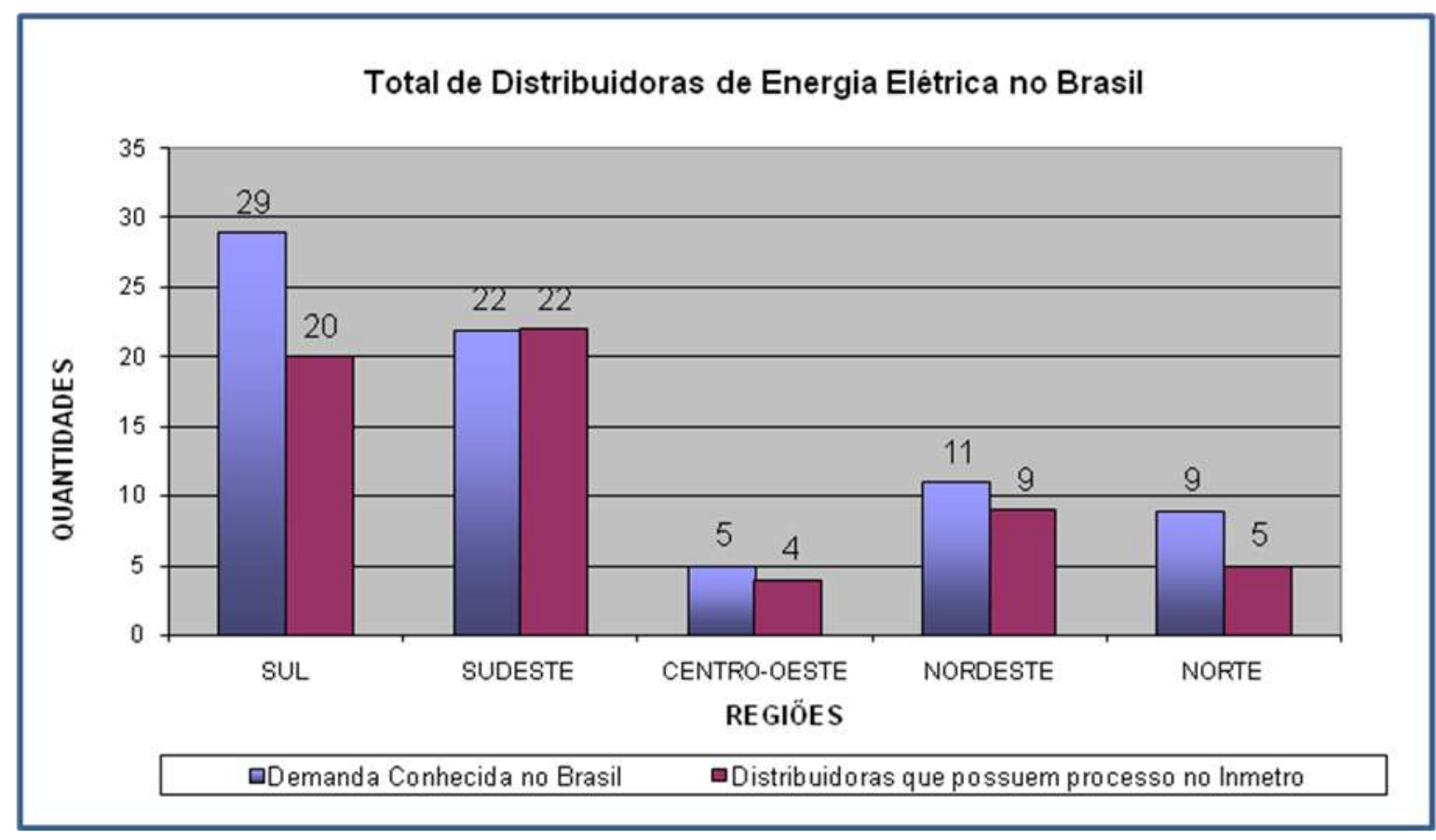

Figura 7: Total de Distribuidoras de Energia Elétrica no Brasil

Fonte: Próprio Autor (2009) 
Vale ressaltar que o número de domicílios é estimado com base na relação habitante/domicílio. No Brasil, espera-se que este valor atinja 2,8 habitantes por domicílio no final do horizonte decenal (Plano Decenal de Expansão de Energia 2019, 2010). Entender as perspectivas de evolução dessa relação é fundamental já que possibilita estimar o número total de domicílios, variável fundamental para a projeção do consumo residencial de energia.

Em consulta realizada à Associação Brasileira de Distribuidores de Energia Elétrica (Abradee), foi obtido o quantitativo de concessionárias e cooperativas distribuidoras de energia elétrica por todo Brasil. A Abradee reúne 48 empresas associadas, entre estatais e privadas, que atendem a $99 \%$ do mercado brasileiro de energia (www.abradee.org.br, acesso em 12 de agosto de 2009). O gráfico da figura 7 mostra as distribuidoras de energia elétrica divididas por região, comparando-se com o quantitativo de empresas que possui processo no Inmetro.

É notório que na maioria das regiões mais de $80 \%$ das distribuidoras do país possuem processo no Inmetro.

\subsection{O DIAGNÓSTICO DA SITUAÇÃO}

A fim de avaliar a atividade de Supervisão Metrológica em nível nacional e obter um diagnóstico da situação assim como propostas de melhoria, a pesquisadora realizou uma entrevista com o especialista em Metrologia Legal e Diretor de Metrologia Legal do IPQ (Instituto Português de Qualidade), Dr. Cartaxo Reis, em sua visita ao Inmetro no mês de julho de 2009. O resultado da entrevista resume-se nas seguintes observações do especialista:

$\checkmark$ Atividades de Metrologia Legal, competências e responsabilidades dispersas em legislação diversa.

$\checkmark$ Defasagem entre a tomada de decisão em nível de Conmetro e a entrada em vigor do RTM correspondente. $\checkmark$ Existência da autorização precária para empresas e laboratórios não certificados / acreditados.

$\checkmark$ Requisitos de imparcialidade e independência não cumpridos por empresas autorizadas (PEA).

$\checkmark$ Para os PEA que possuem laboratório próprio, não foi assegurada a autonomia técnica relativa à organização da qual faz parte nem à influência dos setores comerciais e financeiros.

$\checkmark$ Não há clareza de como são cumpridos os requisitos de serviço ao cliente, ações corretivas, revisão do sistema e melhoria contínua (PEA cujo laboratório próprio tem como cliente somente a própria concessionária).

$\checkmark$ Documentos da Política da Qualidade não refletem claramente a intervenção na Metrologia Legal, além de não haver enfoque claro na melhoria contínua.

$\checkmark$ Esfigmomanômetros são comercializados sem a marca da verificação inicial.

$\checkmark$ Informação no lacre insuficiente. Desejável que contivesse o ano da verificação e símbolos correspondentes às Verificações Iniciais ou às Verificações Subsequientes. (No caso dos hidrômetros, MEE e medidores de gás, esta informação é mais relevante).

$\checkmark$ Possibilidade de avaliação da consistência da produção dos fabricantes de instrumentos de medição durante o processo de aprovação de modelo.

$\checkmark$ Utilização dos Organismos de Certificação de Produtos, de Certificação de SGQ e de Inspeção de Produtos na concessão das autorizações.

A proposta do presente estudo consiste em confrontar estas observações e oportunidades de melhorias apontadas pelo especialista europeu em Metrologia Legal, com a opinião dos tomadores de decisão da Diretoria de Metrologia Legal 
do Inmetro e dos representantes do setor elétrico envolvidos na atividade, e conseqüentemente elaborar ações para os pontos cujas opiniões foram convergentes.

\section{4 - O QUESTIONÁRIO}

A partir das observações e oportunidades de melhoria apontadas pelo especialista em Metrologia Legal na fase anterior foi elaborado um questionário com $\mathrm{o}$ objetivo de se perceber a visão dos gestores da Diretoria de Metrologia Legal, das empresas do setor elétrico autorizadas a realizar autoverificação e dos Postos de Ensaio Autorizados, de forma a encontrar pontos convergentes que serão alvo de ações de melhoria da atividade.

Foram consultados cinco gestores da Diretoria de Metrologia Legal e todos se propuseram a responder o questionário. $\mathrm{O}$ questionário também foi enviado a todos os responsáveis pelas autorizações de AV e PEA e obtivemos resposta de 14 responsáveis, sendo que um foi descartado. Este quantitativo representa $73,8 \%$ do universo de entrevistados.

O questionário foi elaborado utilizandose a escala de medida de Likert. Esta escala foi utilizada na pesquisa para medir os graus de concordância dos respondentes quanto às questões de pesquisa.

$\mathrm{O}$ referido documento possui nove perguntas e se encontra em anexo ao presente artigo.

\section{5 -ANÁLISE DOS RESULTADOS}

A Tabela 2 abaixo mostra os percentuais de concordância de cada questão para cada um dos três grupos respondentes da pesquisa de percepção sobre a atividade de Supervisão Metrológica coordenada pela Diretoria de Metrologia Legal do Inmetro.

Tabela 2 - Percentual de concordância dos três grupos de respondentes:

Fonte: Próprio autor (2009)

\begin{tabular}{|l|c|c|c|}
\hline & INM & AV & PEA \\
\hline$Q_{3}$ & $96 \%$ & $83 \%$ & $94 \%$ \\
\hline$Q_{4}$ & $40 \%$ & $83 \%$ & $86 \%$ \\
\hline$Q_{5}$ & $68 \%$ & $67 \%$ & $86 \%$ \\
\hline$Q_{6}$ & $48 \%$ & $97 \%$ & $97 \%$ \\
\hline$Q_{7}$ & $88 \%$ & $70 \%$ & $100 \%$ \\
\hline$Q_{8}$ & $92 \%$ & $67 \%$ & $66 \%$ \\
\hline$Q_{9}$ & $92 \%$ & $57 \%$ & $63 \%$ \\
\hline$Q_{10}$ & $80 \%$ & $73 \%$ & $89 \%$ \\
\hline$Q_{11}$ & $88 \%$ & $73 \%$ & $74 \%$ \\
\hline
\end{tabular}

A partir da Tabela 2 podemos observar que das nove questões propostas, quatro apresentaram um nível de concordância superior a $70 \%$ para todos os três grupos de respondentes. As respostas às questões $3,7,10$ e 11 foram as que apresentaram uma melhor convergência entre os grupos. Sendo esta convergência positiva, ou seja, tendendo à aceitação do proposto, estes itens serão priorizados na elaboração da ação de melhoria. As demais demonstram discordância de uma ou duas das três partes, e necessitam ser analisadas caso a caso.

\section{6 - A PROPOSTA}

Seguem as ações para aplicação das questões de pesquisa que obtiveram um bom nível de concordância entre todas as partes entrevistadas:

$\checkmark$ Criação de um documento orientativo contendo toda a legislação da atividade de Supervisão Metrológica (Questão 3).

Este documento necessita ser único, porém claro e objetivo. Sugere-se que a base desta documentação seja um esquema que mostra a hierarquia da legislação da atividade, ou seja, leis, resoluções do Conmetro, portarias e Regulamentos Técnicos Metrológicos 
(RTM), além de todos os documentos relacionados à autorização, de acordo com o tipo de instrumento.

$\checkmark$ Expansão do Controle

Metrológico sob a modalidade de Supervisão Metrológica para outros instrumentos de medição (Questão 7).

Para realizar a expansão do Controle Metrológico sob a modalidade de Supervisão Metrológica para outros instrumentos de medição, a primeira ação sem dúvida é a realização de um estudo de impacto no mercado, nas relações de concorrência, na indústria, comércio e consumidores finais, a fim de se detectar a viabilidade da implantação do modelo. Porém, antes deste estudo, que atualmente vem sendo realizado para as demandas que surgem, sugere-se que a Diretoria de Metrologia Legal do Inmetro habitue-se a realizar prospecções da Metrologia Legal no Brasil e no mundo, ou seja, que ao invés de realizar estudos oriundos de demandas que emergem por motivos diversos, assuma uma postura mais pró-ativa, estudando a possibilidade da inserção de instrumentos que já estão sujeitos ao controle metrológico legal na modalidade de Supervisão Metrológica, baseada no crescimento de sua demanda em nível nacional, na capacidade de atendimento a esta demanda via controle metrológico tradicional e nos possíveis impactos mercadológicos desta ação.

$\checkmark$ Avaliação da capacidade do fabricante de realizar os ensaios de verificação inicial do modelo a ser aprovado, durante o processo de Apreciação Técnica do Modelo, para as empresas que já são autorizadas (Questão 10).

Devido ao avanço tecnológico e à rapidez com que as mudanças ocorrem em diversos segmentos da indústria, inúmeras empresas se veem constantemente obrigadas a inovar ou diversificar o seu produto a fim de se manterem competitivas. No caso de empresas cujos produtos estão sujeitos ao controle metrológico legal, ou seja, fabricantes de instrumentos de medição, faz-se necessário aprovar o modelo recém-criado antes que o mesmo entre no mercado, o que significa submetê-lo ao processo de Apreciação Técnica de Modelo (ATM) junto ao Inmetro. Para as empresas que são autorizadas a realizar autoverificação em seus instrumentos de medição, a inserção no escopo de sua autorização do novo modelo recémaprovado requer que a empresa inicie um processo de ampliação de escopo também junto ao Inmetro, após a publicação de sua portaria de Aprovação de Modelo. Atualmente um processo de Apreciação Técnica de Modelo pode levar até oito meses para ser concluído, e de ampliação de escopo, um mínimo de três meses, o que torna a inserção deste modelo de instrumento no mercado extremamente morosa. A proposta é avaliar se a empresa, já autorizada a realizar a AV, é capaz de realizar os ensaios de verificação inicial neste novo modelo, em paralelo ao processo de ATM, a fim de agilizar o processo de ampliação de escopo. Para tal, a Diretoria de Metrologia Legal deve estabelecer um mecanismo interno, ou seja, sem a necessidade de interferência do solicitante, que ao receber um pedido de ATM para um instrumento de medição, a divisão responsável pela execução dos ensaios deste instrumento sinalizasse à divisão responsável pela ampliação de escopo a entrada desta demanda. Este mecanismo pode ser uma programação para a execução desta tarefa no software de gerenciamento de processos já implantado na Dimel. De posse da informação, os técnicos responsáveis pela ampliação de escopo devem iniciar um levantamento dos dados do solicitante, ou seja, o processo de autorização, a infraestrutura atual, a capacidade produtiva versus a quantidade fabricada, além de consultar a divisão responsável pela aprovação do modelo para detectar as possíveis similaridades do novo produto com os já aprovados pertencentes ao escopo da autorização, e consequentemente as possíveis mudanças ou semelhanças no modo de realizar os ensaios. Caso se faça necessário, solicitar uma visita in loco, a fim de avaliar as instalações e comprovar a veracidade das informações obtidas através da 
documentação. Esta ação pode ser simplificada se o técnico que fez a auditoria inicial para a autorização for $o$ mesmo que realizará a ampliação de escopo, ou se a visita for agendada somente para o momento do acompanhamento dos ensaios do primeiro lote de instrumentos. Portarias de aprovação de modelo e de ampliação de escopo devem ser publicadas em paralelo, porém a empresa deve se comprometer com o Inmetro, no sentido de avisar à divisão responsável pela ampliação de escopo (hoje a Disem), da fabricação de seu primeiro lote para comercialização. Assim, a Disem deve enviar um especialista para acompanhar a realização dos ensaios deste lote, antes do mesmo ser comercializado.

$\checkmark$ Treinamento de equipes auditoras dos Organismos de Certificação de Sistemas de Gestão da Qualidade, Organismos de Inspeção e Organismos de Certificação de Produtos, para a realização das auditorias de Supervisão Metrológica, porém mantendo a gestão da atividade e a tomada de decisão sob a responsabilidade da Disem.

Tendo em vista a crescente demanda por autorizações, além do fato que uma vez autorizada o relacionamento entre $o$ Inmetro e as empresas torna-se infindável, com o objetivo de atender a demanda de forma eficaz buscou-se esta solução a partir do diagnóstico do especialista europeu, que foi baseado no modelo de Supervisão Metrológica aplicado a Portugal e a outros países da Europa. Porém, embora a proposta tenha sido corroborada por grande parte dos respondentes, alguns tomadores de decisão do Inmetro e do setor elétrico admitem que a questão necessita ser melhor estudada.

O Inmetro possui a Coordenação Geral de Acreditação (Cgcre), que é a diretoria responsável pela acreditação de Organismos de Inspeção, de Organismos de Certificação de Sistemas de Gestão da Qualidade, de Organismos de Certificação de Produtos, dentre outros. A proposta consiste na Diretoria de
Metrologia Legal, a partir da interação com a Cgcre, utilizar o conhecimento destes organismos, além de sua mão-deobra já conhecida e treinada, ou seja, seus auditores, para realizar as avaliações de Supervisão Metrológica nos Postos de Ensaios Autorizados e nos autorizados à autoverificação oferecendo-lhes o treinamento específico e somando a estas avaliações os requisitos de Metrologia Legal.

\section{CONSIDERAÇÕES FINAIS}

O objetivo principal da pesquisa foi propor melhorias para a atividade de Supervisão Metrológica de forma a aprimorar o atendimento ao setor elétrico do Brasil demandante desta atividade. Para o alcance deste objetivo foi realizado o mapeamento do processo de Supervisão Metrológica, foi feito um levantamento documental e mostrado o panorama atual da atividade. A partir destas informações, o especialista em Metrologia Legal europeu realizou uma consultoria para o Inmetro sobre a Metrologia Legal no Brasil e levantou mais observações inerentes à atividade. Dos apontamentos da consultoria foi elaborado um questionário de pesquisa com o objetivo de detectar a percepção do setor elétrico sobre o assunto e confrontar esta percepção com a dos dirigentes da Diretoria de Metrologia Legal do Inmetro, cujos resultados geraram uma proposta de melhoria. Das nove questões da pesquisa, quatro convergiram positivamente.

Estas quatro questões foram:

$\checkmark$ Criação de um documento orientativo contendo toda a legislação da atividade.

$\checkmark$ Expansão do Controle Metrológico sob a modalidade de Supervisão Metrológica para outros instrumentos de medição.

$\checkmark$ Avaliação da capacidade do fabricante de realizar os ensaios de verificação inicial do modelo a ser aprovado durante o processo de Apreciação Técnica do Modelo, para as empresas que já são autorizadas. 
$\checkmark$ Treinamento de equipes auditoras dos Organismos de Certificação de Sistemas de Gestão da Qualidade, Organismos de Inspeção e Organismos de Certificação de Produtos, para a realização das auditorias de Supervisão Metrológica, porém mantendo a gestão da atividade e a tomada de decisão sob a responsabilidade da Disem.

Todas as propostas elaboradas para estas questões mostram como dinamizar o processo de Supervisão Metrológica para o atendimento ao setor elétrico de forma a torná-lo mais eficaz, atingindo assim o objetivo principal do estudo.

Atualmente, em consonância com as Diretrizes Estratégicas para a Metrologia brasileira 2008-2012 no âmbito da Metrologia Legal, no que diz respeito ao acompanhamento do intenso avanço tecnológico dos instrumentos de medição, a Supervisão Metrológica para instrumentos no campo da eletricidade já se expandiu para o controle dos Sistemas de Distribuição de Medição de Energia Elétrica (SDMEE) que consistem em conjuntos de vários medidores de energia elétrica acoplados em uma única unidade que leva a medição de energia de várias residências para uma única central, simultaneamente e por meio remoto, transferindo a necessidade de se garantir a confiabilidade da medição não somente pelo conhecimento da tecnologia eletrônica como também pela avaliação desses softwares. A Diretoria de Metrologia Legal do Inmetro já dispõe de uma equipe especializada em analisar e aprovar esses softwares e que, quando necessário, compõe a equipe auditora para a realização da Supervisão metrológica nos fabricantes deste tipo de instrumento.

Esta pesquisa abre oportunidade para que outros trabalhos sejam desenvolvidos, considerando a relevância do assunto e a necessidade de se obter respostas rápidas aos problemas que surgem. Como propostas para trabalhos futuros podem se destacar: $\checkmark$ Realizar estudos similares de Benchmarking com outros países europeus, visualizando $\mathrm{o}$ funcionamento da atividade na prática, ou seja, com visitas in loco, entrevistas com os principais atores, sejam tanto dos órgãos gestores como dos demandantes da atividade e agentes intermediários do processo, com o propósito de levantar os principais pontos críticos e as principais ocorrências de sucesso.

$\checkmark$ Após estas propostas implementadas, estabelecer meios para observar as melhorias ocorridas, ou seja, para fazer a comparação de alguns indicadores antes e depois da implementação das propostas.

$\checkmark$ Ampliar a pesquisa de percepção no sentido de se levantar mais apontamentos que podem ser causas de insatisfação dos envolvidos, ou que podem ser fatores que poderão gerar melhorias no processo.

\section{REFERÊNCIAS}

ASSOCIAÇÃO BRASILEIRA DA INDÚSTRIA ELÉTRICA E ELETRÔNICA - ABINEE. Estatísticas. Disponível em: www.abinee.org.br. Acesso em: 17 jul. 2009.

ASSOCIAÇÃO BRASILEIRA DE NORMAS TÉCNICAS - ABNT. Sistemas de Gestão da qualidade: Requisitos. NBR ISO 9001:2000. Rio de Janeiro, 2000. 30p

ASSOCIAÇÃO BRASILEIRA DE NORMAS TÉCNICAS - ABNT. Requisitos gerais para competência de laboratórios de ensaios e calibração: NBR ISO/IEC 17025. Rio de Janeiro, 2001. $19 \mathrm{p}$

CONSELHO NACIONAL DE METROLOGIA, NORMALIZAÇÃO E QUALIDADE INDUSTRIAL

Conmetro. Diretrizes Estratégicas para a Metrologia Brasileira 2008-2012. Rio de 
Janeiro, 2008. 46p. Disponível em:www.inmetro.gov.br/noticias/conteud o/diretrizesEstrategicas.pdf. Acesso em: 28 nov. 2012.

\section{MINISTÉRIO DE MINAS E ENERGIA} I EMPRESA DE PESQUISA ENERGÉTICA. Plano Decenal de Expansão de Energia 2019. Brasília: MME/EPE, 2010. 354p.Disponível em: http://www.mme.gov.br/mme/galerias/ar quivos/noticias/2010. Acesso em: 28 ago. 2012

BRASIL - Lei 9.933, de 20 de dezembro de 1999. Dispõe sobre as competências do Conmetro e do Inmetro, institui a taxa de serviços metrológicos, e dá outras providências. Diário Oficial da República Federativa do Brasil, Brasil, DF.

BRASIL -Lei $\mathrm{n}^{\mathrm{o}} 10.829$ de 23 de dezembro de 2003. Reajusta os valores das Taxa de Serviços Metrológicos, e dá outras providências.

BRASIL -Resolução Conmetro $\mathrm{n}^{\circ} 013$, de 20 de dezembro de 2006. Autoriza a utilização da supervisão metrológica como forma de execução do controle legal de instrumentos de medição para determinadas classes de instrumentos.

BRASIL -Resolução Conmetro $n^{\circ}$ 04, de 6 de setembro de 2007. Autoriza a expansão da utilização da supervisão metrológica como forma de execução do controle legal de instrumentos de medição para esfigmomanômetros e cronotacógrafos.

BRASIL -Portaria Inmetro $\mathrm{n}^{\circ} 66$ de 13 de abril de 2005. Estabelece as condições que devem ser atendidas pelas organizações que requeiram a concessão ou manutenção de autorização para executar, sob supervisão metrológica do Inmetro, os ensaios inerentes à verificação dos instrumentos de medição, sujeitos a controle metrológico obrigatório, nos termos da regulamentação metrológica aplicável.

BRASIL -Portaria Inmetro $\mathrm{n}^{\circ} 163$ de 06 de setembro de 2005. Vocabulário Internacional de Termos de Metrologia Legal. Rio de Janeiro, 2005, $4^{\mathrm{a}} \mathrm{Ed}$.

RÉCHE, M. M. Novas Formas de Atuação para a Metrologia Legal no Brasil. Rio de Janeiro, 2004. 112p.

RODRIGUES, S. C. A. Fatores críticos de sucesso para o lançamento de serviços de comunicação móvel de dados nas operadoras de telefonia móvel celular no Brasil. Niterói, 2005, 260 f. Tese (Mestrado em Engenharia de Produção) Escola de Engenharia, Universidade Federal Fluminense, Niterói, 2005.

TIMMINS, A.S.P. Propostas de melhoria para a supervisão metrológica baseadas nas percepções do setor elétrico do brasil. 2009. 141 f. Dissertação (Mestrado em Sistemas de Gestão) - Universidade Federal Fluminense, Niterói. 2009. 
Prezados,

Este questionário possui por finalidade:

Identificar oportunidades de melhoria na atividade de Supervisão Metrológica gerenciada pelo Inmetro,

Verificar a opinião das partes interessadas quanto a possíveis mudanças estruturais no referido processo de forma a subsidiar uma posterior tomada de decisão.

Solicito que o questionário seja respondido com a maior brevidade possível. Todos os dados informados pelos respondentes serão tratados com total confidencialidade. Suas respostas serão combinadas com as demais respostas e apresentadas em sumário, sem a menor possibilidade de identificação de informações específicas de cada usuário ou da empresa respondente. Enfatizo que as ações a serem tomadas visam o benefício de todos.

1.Empresa:

2. Modalidade da Autorização: AV: Autoverificação
( ) AV

PEA: Posto de Ensaio Autorizado

Marque com um (X) uma única alternativa e caso considere necessário, complemente sua resposta no item em aberto que se encontra abaixo de cada pergunta.

3. Contexto:A legislação que rege o controle metrológico sob a modalidade da Supervisão Metrológica atualmente é composta por vários documentos (Resoluções Conmetro 13/06, 04/07, Portaria nº66/05, Portaria n²84/08, Lei nº 10829/03, Lei no 9933/99, etc.).

Questão:Estamos propondo a criação de um documento orientativo com toda a documentação, contendo sua natureza e nível hierárquico, pois facilitará a compreensão da legislação. Você concorda com esta ação?
( ) 5 - Concordo integralmente
( ) 4 - Concordo parcialmente
( ) 3 - Sou indiferente
( ) 2 - Discordo parcialmente
( ) 1 - Discordo integralmente
( ) N - Não sei opinar

Justifique sua resposta:

4. Contexto:A Portaria Inmetro $n^{\circ} 066 / 05$, prevê a possibilidade de empresas solicitantes da autorização para Auto Verificação que não possuam a certificação ISO 9001:2008 ou Concessionárias postulantes à autorização para Posto de Ensaio Autorizado que não possuam a acreditação pela NBR ISO IEC 17025:2005, recebam uma autorização temporária, denominada precária, desde que cumpram os itens 2.2.a, b, e c do RTM a que se refere a Portaria $n^{\circ}$ 066/05 ( $\$ 3^{\circ}$ do Art. $2^{\circ}$ da Portaria 066/05).

ENGEVISTA, V. 16, n. 3, p.292-313, Setembro 2014 
Afirmação:A eliminação da exigência de avaliação destes itens (2.2a, 2.2b e 2.2c) do RTM a que se refere a Portaria $n^{\circ} 66 / 05$ no momento da auditoria de autorização, para empresas que ao requererem a autorização já possuam a devida certificação / acreditação, reduzirá a atuação dos técnicos da Dimel, agilizando o processo de autorização.

Questão: Você concorda com esta afirmação?

( ) 5 - Concordo integralmente

( ) 4 - Concordo parcialmente

( ) 3 - Sou indiferente

( ) 2 - Discordo parcialmente

( ) 1 - Discordo integralmente

( ) N - Não sei opinar

Explique sua resposta:

5. Afirmação: O cumprimento dos itens da norma NBR ISO 17025:2005 que tratam da infra-estrutura laboratorial, rastreabilidade dos padrões e equipamentos utilizados nos ensaios e procedimentos técnicos para realização dos ensaios, leva ao atendimento aos itens 2.2a, 2.2b, 2.2c do RTM a que se refere a Portaria Inmetro $n^{\circ}$ 066/05.

Questão: Você concorda com esta afirmação?

( ) 5 - Concordo integralmente

( ) 4 - Concordo parcialmente

( ) 3 - Sou indiferente

( ) 2 - Discordo parcialmente

( ) 1 - Discordo integralmente

( ) N - Não sei opinar

Justifique sua resposta:

6. Afirmação: Há uma DEFASAGEM entre a tomada de decisão por mudanças no processo de supervisão metrológica e a publicação e entrada em vigor da legislação que revisa a regulamentação da atividade.

Questão: Você concorda com esta afirmação?

( ) 5 - Concordo integralmente

( ) 4 - Concordo parcialmente

( ) 3 - Sou indiferente

( ) 2 - Discordo parcialmente

( ) 1 - Discordo integralmente

( ) N - Não sei opinar

Justifique sua resposta:

ENGEVISTA, V. 16, n. 3, p.292-313, Setembro 2014 
7. Contexto: Atualmente a Supervisão Metrológica aplica-se aos fabricantes de instrumentos de medição de energia elétrica, água, gás, cronotacógrafos e esfigmomanômetros e concessionárias que oferecem serviços nas três primeiras áreas.

Questão: Porém, você concorda com a possibilidade de futuramente expandirmos esta modalidade de controle metrológico para outros instrumentos de medição?

( ) 5 - Concordo integralmente

( ) 4 - Concordo parcialmente

( ) 3 - Sou indiferente

( ) 2 - Discordo parcialmente

( ) 1 - Discordo integralmente

( ) N - Não sei opinar

Justifique sua resposta:

8. Contexto: Atualmente, os Postos de Ensaio Autorizados são concessionárias que possuem laboratórios próprios ou contratam o serviço de laboratórios externos. Logo, a responsabilidade jurídica pelos ensaios realizados é sempre da concessionária.

Ação: Estamos avaliando a possibilidade de a autorização para PEA ser dada aos laboratórios, e não mais às concessionárias. Esta ação eliminaria a questão da imparcialidade e independência, já que as concessionárias não estariam mais comercializando os medidores que elas próprias ensaiam.

Questão: Qual a sua opinião sobre esta ação?

( ) 5 - Concordo integralmente

( ) 4 - Concordo parcialmente

( ) 3 - Sou indiferente

( ) 2 - Discordo parcialmente

( ) 1 - Discordo integralmente

( ) N - Não sei opinar

Justifique / complemente sua resposta:

9. Contexto: Os lacres dos instrumentos de medição contêm o logo do Inmetro e da própria empresa.

Ação: Seria desejável que contivessem o ano em que a verificação foi realizada, e que existissem símbolos correspondentes às verificações iniciais ou às verificações após reparos, para um melhor controle das autoridades competentes ao longo de sua vida útil. 
Questão: Você concorda com esta ação?

( ) 5 - Concordo integralmente

( ) 4 - Concordo parcialmente

( ) 3 - Sou indiferente

( ) 2 - Discordo parcialmente

( ) 1 - Discordo integralmente

( ) N - Não sei opinar

Explique sua resposta:

10. Contexto: Empresas fabricantes de instrumentos de medição que são autorizadas a realizar auto-verificação possuem seu escopo de instrumentos autorizados (por modelo) claramente definido em sua portaria de autorização. A comercialização de um novo modelo nos moldes da auto-verificação requer, após a aprovação do mesmo, que a empresa solicite ao Inmetro a ampliação do escopo da autorização.

Ação: Sendo assim, durante o processo de Apreciação Técnica do Modelo, estamos estudando a possibilidade de avaliar a capacidade do fabricante de realizar os ensaios de verificação inicial do modelo a ser aprovado, para as empresas que já são autorizadas.

Questão: Você concorda com esta ação?

( ) 5 - Concordo integralmente

( ) 4 - Concordo parcialmente

( ) 3 - Sou indiferente

( ) 2 - Discordo parcialmente

( ) 1 - Discordo integralmente

( ) N - Não sei opinar

Complemente sua resposta:

11. Contexto: A responsabilidade pelas autorizações de AV/PEA é da Diretoria de Metrologia Legal (Dimel), na figura da Divisão de Serviços Metrológicos (Disem), que hoje dispõe de 5 auditores e conta com o apoio das divisões da Dimel responsáveis pelas aprovações dos modelos dos instrumentos sujeitos ao controle metrológico legal, que cedem seus especialistas para o acompanhamento das auditorias.

A Coordenação Geral de Acreditação (Cgcre) é a parte do Inmetro responsável pela acreditação dos Organismos de Certificação de Sistemas de Gestão da Qualidade (Ex. Fundação Vanzolini, Fundação Getúlio Vargas), Organismos de Inspeção, Organismos de Certificação de Produtos, dentre outros, em diversas normas, como a NBR 17025, NBR 17020, NBR 45011, etc.

Ação: Para aumentar a eficiência do processo, dentre outras ações, estudamos a possibilidade de, em consonância com a Cgcre, treinarmos equipes auditoras dos Organismos de Certificação de Sistemas de Gestão da Qualidade, Organismos de Inspeção e Organismos de Certificação de Produtos,para a realização das auditorias de Supervisão Metrológica, porém mantendo a gestão da atividade e a tomada de decisão sob a responsabilidade da Disem. 
Questão: Você concorda com esta ação?
( ) 5 - Concordo integralmente
( ) 4 - Concordo parcialmente
( ) 3 - Sou indiferente
( ) 2 - Discordo parcialmente
( ) 1 - Discordo integralmente
( ) N - Não sei opinar

Complemente sua resposta:

Obrigada pela atenção !!! 